\title{
Characterization and Biological Performance of Marine Sponge Collagen
}

Kelly Rossetti Fernandes ${ }^{1 *}$

https://orcid.org/0000-0003-2851-6896

Julia Risso Parisi ${ }^{1}$

https://orcid.org/0000-0002-4325-0638

Matheus de Almeida Cruz $^{2}$

https://orcid.org/0000-0002-9032-9111

Paulo Roberto Gabbai-Armelin ${ }^{2}$

https://orcid.org/0000-0003-4802-0062

Tiago Akira Tashiro de Araújo

https://orcid.org/0000-0003-2960-8186

Alan de França Santana ${ }^{2}$

https://orcid.org/0000-0001-8213-8262

Ingrid Regina Avanzi ${ }^{2}$

https://orcid.org/0000-0001-5948-1484
Francisca Rayanne Silva-Freitas ${ }^{2}$

https://orcid.org/0000-0001-8690-3881

Alessandra Mussi Ribeiro ${ }^{2 \star}$
https://orcid.org/0000-0002-7697-5766

Giovanna Caroline Aparecida do Vale ${ }^{1}$

https://orcid.org/0000-0002-5375-1241

Carlos Alberto Fortulan ${ }^{3}$

https://orcid.org/0000-0002-2259-9910

Renata Neves Granito ${ }^{2}$

https://orcid.org/0000-0002-2094-3845

Ana Claudia Muniz Renno ${ }^{2}$

https://orcid.org/0000-0003-2358-0514

${ }^{1}$ Federal University of São Carlos (UFSCar), Department of Physiotherapy, São Carlos, São Paulo, Brazil; ${ }^{2}$ Federal University of São Paulo (UNIFESP), Department of Biosciences, Santos, São Paulo, Brazil; '3ão Carlos School of Engineering, Department of Mechanical Engineering, São Carlos, São Paulo, Brazil.

Editor-in-Chief: Paulo Vitor Farago

Associate Editor: Paulo Vitor Farago

Received: 2020.09.11; Accepted: 2021.02.23.

*Correspondence: kellyrf10@yahoo.com.br; Tel.: +55 1633518111 (K.R.F.)

\section{HIGHLIGHTS}

- Marine collagen - spongin - extract from specimens of the sponge Aplysina fulva.

- Spongin has physicochemical and morphological properties analogous to human collagen.

- Spongin is an alternative source of collagen for tissue engineering proposals.

Abstract: This study characterized the morphological aspects of marine collagen - spongin (SPG) extract from marine sponges, as well as, evaluating its in vitro and in vivo biological performance. Aplysina fulva marine sponge was used for the SPG extraction. It was investigated the physicochemical and morphological properties of SPG by using scanning electron microscopy, Fourier transform infrared spectroscopy, X-ray diffraction and compared to PMMA and bovine collagen. Additionally, the SPG cytotoxicity and its influence on cell proliferation, through in vitro tests. Moreover, the in vivo biological response was investigated using 
an experimental model of tibial bone defect. The results demonstrated that SPG presented an irregular granular aspect, with a composition of $\mathrm{OH}, \mathrm{C}=\mathrm{O}, \mathrm{NH}, \mathrm{CN}$ and an amorphous profile. Also, in vitro viability results for the L929 and MC3T3 cell lines cultured with SPG extracts demonstrated normal growth in comparison to controls, except for MC3T3 viability at day 3. For in vivo analysis, using tibial bone defects in rats, SPG treated animals presented an increased rate of material resorption and higher granulation and bone formation deposition in the region of the defect, mainly after 45 days. As a conclusion, SPG was successfully extracted. The in vitro and in vivo studies pointed out that SPG samples produced an increase in L929 and MC3T3 viability and improved the performance in tibial bone defects. It can be concluded that SPG can be used as a bone graft for bone regeneration.

Keywords: spongin; Aplysina fulva; tibial bone defects; bone regeneration; biocompatibility.

\section{INTRODUCTION}

It is well known that collagen is the most abundant protein in animals and it is involved in structural integrity of many tissues [1]. Based on its biocompatibility and non-cytotoxicity, collagen-derived grafts are extremely suitable for the field of regenerative medicine (TERM) to treat human health issues in the medical, dental and pharmacological areas [1]. Collagen biomaterials have many medical applications such as skin grafts, carriers for drug delivery, bone substitutes, antithrombogenic surfaces and immobilization of therapeutic enzymes $[2,3,4]$.

Collagen can be originated from many sources, including bovine and porcine origins [2]. However, their use involves some concerns especially due to the risk of disease transmission such as bovine spongiform encephalopathy (BSE) [2]. In this context, alternative collagen has been explored mainly the ones from marine origin, especially from sponges, being considered highly attractive by the industry as an important alternative source [2,5].

Marine sponges are sessile animals from the phylum Porifera, presenting a very interesting structure and composition, being formed by an inorganic and organic part [6]. The mineral part is constituted mainly by amorphous non-crystalline silica $\left(\mathrm{SiO}_{2} / \mathrm{H}_{2} \mathrm{O}\right)$ or calcium carbonate $(\mathrm{CaCO} 3)$ [7]. The organic part is compound by special collagen fibers called spongin (SPG), which is a collagenous protein synthesised by spongocytes. Also, it is known that SPG fibers, disposable in different arrangements, confer the flexibility observed in these animals [7]. In addition, SPG has been considered to be analogous to type XIII human collagen [8]. Many works have been showing that collagen fibers of the marine sponge skeleton indeed provide a suitable framework for the attachment, migration and proliferation of osteoblasts $[8,9,10]$. More recently, Pozzolini et al. [1] developed a protocol of SPG extraction from Chondrosia reniformis Nardo marine sponges and manufactured a collagenous membrane, able of supporting fibroblast and keratinocytes cell proliferation through in vitro studies.

Despite the positive evidence of SPG from the specie Aplysina fulva toward the stimulation of tissues, many of the physicochemical and morphological characteristics, in vitro biocompatibility and in vivo response are not well known yet. Thus, the aim of this study is: i) to characterize by SPG by using scanning electron microscopy (SEM), Fourier transform infrared spectroscopy, X-ray diffraction (XRD); ii) to study SPG cytotoxicity and its influence on cell proliferation, through in vitro tests, iii) in vivo biological response using an experimental model of tibial bone defect. We hypothesized that SPG presents proper osteopromotive properties to be used as a new substrate for tissue engineering applications.

\section{MATERIAL AND METHODS}

\section{Spongin extraction}

Marine sponge (specie Aplysina fulva) was used for the SPG extraction. Samples were collected in Praia Grande (23o49'23.76 "S, 45025'01.79" W, São Sebastião, Brazil). A scalpel blade was used for collecting the samples, which were immediately washed with sea water and transported to the lab in thermal boxes (with sea water). Then, samples were washed 3 times with Milli-Q water in order to remove cell debris and were immediately stored in a freezer $\left(-20^{\circ} \mathrm{C}\right)$. For SPG extraction, the marine sponges were cut into small pieces and inserted in a box with Tris- $\mathrm{HCl}$ buffer $(100 \mathrm{mM}, \mathrm{pH}$ 9.5, $10 \mathrm{mM}$ EDTA, $8 \mathrm{M}$ urea, $100 \mathrm{mM} 2$ mercaptoethanol). $\mathrm{pH}$ was adjusted to 9 (with the addition of $\mathrm{NaOH}$ solution) and then, solution was transferred into a stirred beaker. After $24 \mathrm{hrs}$, the solution was centrifuged for 5 minutes at $2^{\circ} \mathrm{C}$. Then the supernatant was removed for analysis and the pellet was discharged. Acetic acid solution was added to adjust $\mathrm{pH}$ to 4 . At the end, the solution was lyophilized for preservation and stored until use [11]. 


\section{Bovine collagen}

For the in vitro studies, commercially fibers of bovine collagen type I (COL) (US Biological Life Sciences) were used in this study as a control.

\section{Preparation of composites}

The in vitro study was performed using scaffolds manufactured with SPG and bovine collagen. For scaffold manufacturing, the methodology used in previous works was used [12-15]. Briefly, SPG and bovine Col were separately weighted. Afterwards, aggregating reagent was added to both SPG and Collagen poly(methyl methacrylate) (PMMA) and mixed. For creating porosity, Carboxymethyl cellulose (CMC)) was used as a porogenic agent (porosity of $60 \%$ ). To this mixture, distilled $\mathrm{H}_{2} \mathrm{O}$ was added and the solution was inserted in a silicone mold with a spatula (at different percentages-corresponding groups). After mixturing, methyl methacrylate monomer (MMA) was added and the mixture was rapidly transferred to another silicon mold $(6 \mathrm{~mm}$ diameter $\times 2 \mathrm{~mm}$ height for the in vitro tests and $3 \mathrm{~mm}$ diameter $\times 1 \mathrm{~mm}$ height for the in vivo studies). Subsequently, the molds were sealed and inserted in a pressure air chamber (at $0.6 \mathrm{MPa}$ for 30 mins). The molds were then vacuum dried during 15 minutes and produced scaffolds were removed and sterilized by ethylene oxide (Acecil, Campinas, SP, Brazil). The following amount of materials was used: PMMA (0.236g), MMA (0.472), SPG and Collagen (0.560), CMC (0.043) and water (0.565).

\section{Material characterization}

\section{Scanning electron microscopy (SEM)}

SEM was used for analyzing the morphology of the scaffolds (ZEISS LEO 440 microscope, $20 \mathrm{kV}, 2.82$ A).

\section{Fourier transform infrared spectroscopy (FTIR)}

FTIR (Perkin-Elmer 1700 UK) was performed for the analysis of the chemical bonds present in both collagen samples (both SPG and bovine). Samples were scanned 100 times for each FTIR measurement (at the range of $400-4000 \mathrm{~cm}^{-1}$ with a resolution of $2 \mathrm{~cm}^{-1}$ ) and the spectrum acquired was the average of all these scans.

\section{$X$-ray diffraction $(X R D)$}

XRD (Philips, Cu-Ka, $45 \mathrm{kV}, 30 \mathrm{~mA}$ ), at $2 \theta$ range, $5-60^{\circ}$, to investigate the crystalline structures of SPG samples.

\section{Cell culture studies}

The indirect assay, using the extracts of the materials, was used for analyzing the cytotoxicity of SPG and bovine collagen [16]. Before analysis, scaffolds were sterilized using ultraviolet irradiation (UV) during $24 \mathrm{~h}$ and then, they $(\mathrm{n}=5)$ were maintained in standard $\alpha$-MEM culture medium (Alpha Minimal Essential Medium with $10 \%$ fetal bovine serum and $1 \%$ antibiotic; Vitrocell, Campinas, Brazil), with $1 \% \beta-$ Glycerophosphate, 1\% 2-phospho-L-ascorbic acid trisodium salt and $0.1 \%$ dexamethasone) for $24 \mathrm{hrs}$, in an incubator, at $37^{\circ} \mathrm{C}$ and $5 \% \mathrm{CO}_{2}$. After this period, a $0.22 \mu \mathrm{m}$ filter (Kasvi, Curitiba, Brazil) was used for filtering the extracts. Control without material was incubated under the same conditions described above.

For this work, 2 cell lines were used: mouse calvaria-derived MC3T3-E1 subclone 14 pre-osteoblastic cells and murine fibroblasts cells (L929). MC3T3-E1 and L929 cells (BCRJ, RJ, Brazil) were cultured in standard procedures. After reaching $80 \%$ of confluence, cells were detached with trypsin and seeded (with a density of $5 \times 10^{3}$ cells $/ \mathrm{cm}^{2}$ ) in 24-well plates ( $1 \mathrm{ml}$ of supplemented standard medium per well). After $24 \mathrm{~h}$, the used medium was substituted by $1 \mathrm{ml}$ of scaffold composites previously collected. Cells were cultured in the extracts in 3 experimental periods ( 1,3 and 6 days).

AlamarBlue ${ }^{\circledR}$ assay (Thermo Fisher Scientific, São Paulo, Brazil) was used as cell viability analysis through the addition of $500 \mu \mathrm{l}$ of $10 \%$ alamarBlue ${ }^{\circledR}$ solution to each well and incubated in dark during $3 \mathrm{~h}$. The next step was the addition of $200 \mu \mathrm{l}$ of solution (in duplicate) to each well and the measurements in the microplate spectrophotometer (Bio-Tek Instruments, Inc.), with the wavelengths of 570 and $600 \mathrm{~nm}$. The proliferation rates were calculated as the percentage of the reduction of alamarBlue ${ }^{\circledR}$, according to manufacturer's instructions. Experiments were performed in triplicate. 


\section{In vivo study}

Thirty-two male Wistar rats (12 weeks, weight $300-350 \mathrm{~g}$ ) were randomly distributed into 2 groups, with 2 different experimental periods, 15 and 45 days ( $n=8$ for each subgroup). The groups were constituted as following: animals receiving the implant of PMMA (positive control) and animals receiving the implants of SPG. All animals were subjected to the surgical procedure during this experiment to induce the unilateral noncritical tibial bone defect. After surgery, animals were kept under controlled temperature (22 $\left.\pm 2{ }^{\circ} \mathrm{C}\right), 12$ $\mathrm{h}$ light-dark periods and with free access to water and food. This study was approved by the Animal Care Committee guidelines of the Federal University of São Paulo (CEUA no 1952071216). After 15- or 45-days post-surgery animals were euthanized.

\section{Surgical procedures}

Before the surgical intervention, animals were submitted to anaesthesia with ketamine $(80 \mathrm{mg} / \mathrm{kg})$, xylazine $(8 \mathrm{mg} / \mathrm{kg})$, acepromazine $(1 \mathrm{mg} / \mathrm{kg})$ and fentanyl $(0.05 \mathrm{mg} / \mathrm{kg})$. After this procedure, animals had their hind limbs shaved, washed and disinfected with povidone-iodine. Using aseptic techniques, an incision was made on the skin for exposing the medial compartment of the tibia. A motorized drill (Beltec®, Araraquara, SP, Brazil) was used to perform the bilateral bone defects at the upper third of the tibia (10 $\mathrm{mm}$ distal of the knee joint). The pre-set implants were placed in the created defect $(3 \mathrm{~mm}$ diameter $\times 1 \mathrm{~mm}$ height), according to a randomization scheme. Finally, wounds were closed with resorbable Vicryl® 5-0 (Johnson \& Johnson, St.Stevens-Woluwe, Belgium) and rats were treated with post-surgery cares (i.m., 0.05 mgkg buprenorphine (Temgesic; Reckitt Benckiser Health Care Limited, Schering Plough, Hoddesdon, United Kingdom) after the returning to their cages.

\section{Histopathological analysis}

After the euthanasia with the method of $\mathrm{CO} 2$ suffocation, the right tibiae was removed, fixed in $10 \%$ buffer formalin (Merck, Darmstadt, Germany) for 24 hours, washed and submitted to the decalcified process in $10 \%$ EDTA solution (ethylenediaminetetraacetic acid, Labsynth $\AA$, Diadema, Brazil) for 40 days. Samples were inserted in paraffin blocks and thin sections $(5 \mu \mathrm{m})$ were prepared using a microtome (Leica Microsystems SP 1600, Nussloch, Germany). Sections were stained with hematoxylin and eosin (Merck, Darmstadt, Germany) and examined using light microscopy (Leica Microsystems AG, Wetzlar, Germany, Darmstadt-Germany) $[17,18,19]$ Qualitative analysis of the laminae was performed using the following criteria: presence of granulation tissue, newly formed bone and material degradation (analysis was performed in a blinded way, KRF and JRP).

\section{Histomorphometric analysis}

The software OsteoMeasure System (Osteometrics, Atlanta, GA, USA) was used for the sample analysis. The following parameters were evaluated: bone volume per tissue volume (BV/TV, \%), osteoblast surface per bone surface (Ob.S/BS, \%) and for number of osteoblast per tissue area (N.Ob/T.Ar, \%) to measure the effects of the treatment in the process of bone healing (the analysis was performed by one experienced observer, JRP, in a blinded way).

\section{Biomechanical test}

Biomechanical analysis was performed through the 3-point bending test performed on the left tibia of the animals (Instron® Universal Testing Machine (USA, model 4444). Tibiae were placed on a 3.8-cm metal device, which provided a 1.8-cm-distant double support on the bone diaphysis. A load cell was perpendicularly positioned at the exact site of the bone defect and the following variables were analyzed: maximum load $(\mathrm{N})$, resilience $(\mathrm{N} / \mathrm{nn} 2)$ and tenacity $(\mathrm{J})[20]$.

\section{Statistical Analysis}

Mean \pm standard deviations (SD) were used to express the data. Statistical analyses were performed using GraphPad Prism 6 (GraphPad Software, San Diego, CA, USA). The distribution was checked using the Shapiro-Wilk normality test and the Kruskal-Wallis test and Dunn post hoc were used for non-parametric data. One-way analysis of variance (ANOVA) and Tukey multiple comparisons post-tests were used for parametric data. Test $t$ was used for histomorphometry and biomechanical analysis. Differences of $p \leq 0.05$ were considered for demonstrating significance. 


\section{RESULTS}

\section{SEM}

SEM results are depicted in Figure 1 (with a magnitude of 200x-A1, B1 and C1 and 500x- A2, B2 and C2). PMMA characteristics spheres could be observed in the pure polymer (Figure 1.A1). After mixing with other materials and polymerization, PMMA could still be noticed but with a flatter aspect (Figures 1.A2, B2 and C2). Additionally, pores were found in all composites. Fibers of the bovine COL could be seen in COLplain material and in the composites containing this organic component (Figure 1.B1 and B2). SPG presented a smoother and more granulous form compared to bovine COL (Figures 1.C1 and C2). Both organic components, i.e. COL and SPG, presented irregular and heterogeneous morphology.

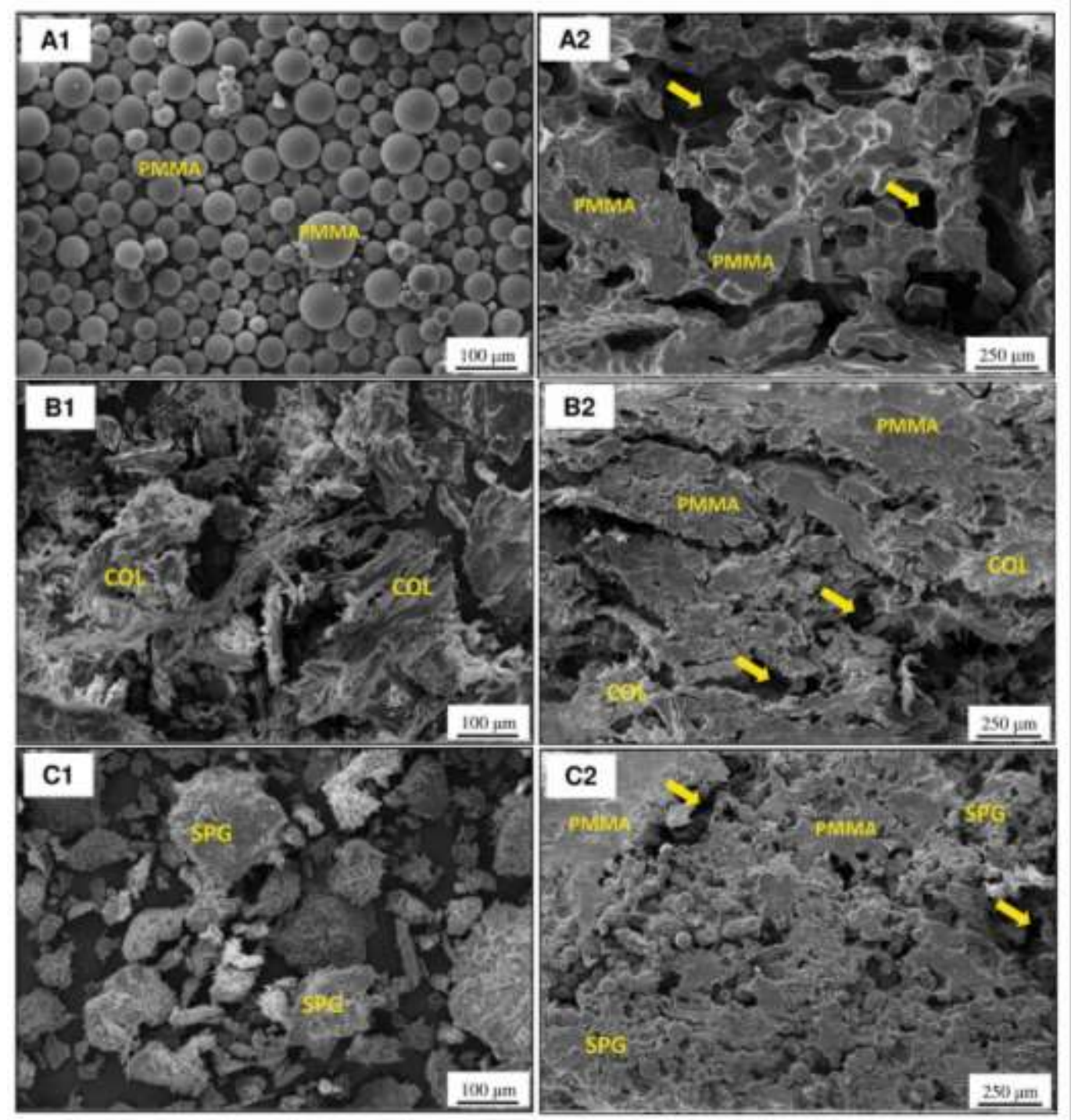

Figure 1. SEM micrographs of pure materials (A1) PMMA, (B1) COL and (C1) SPG) used in powder form. Scaffolds of (A2) PMMA, (B2) COL and (C2) SPG. Bar represents 100 or $250 \mu \mathrm{m}$ at magnifications of 200x and 500x respectively. PMMA particles (PMMA), Collagen fibers (COL), Spongin particles (SPG) and pores (arrows).

\section{FTIR}

FTIR spectra of SPG indicated absorption peaks for this marine organic component at 3522, 1644, 1510 and 1258 wavenumber $(\mathrm{cm}-1)$ related to the chemical groupings of $\mathrm{OH}, \mathrm{C}=\mathrm{O}, \mathrm{NH}$ and $\mathrm{CN}$ respectively. Additionally, an N-H axial deformation was detected around $2900 \mathrm{~cm}-1$ (Figure 2). 
FTIR

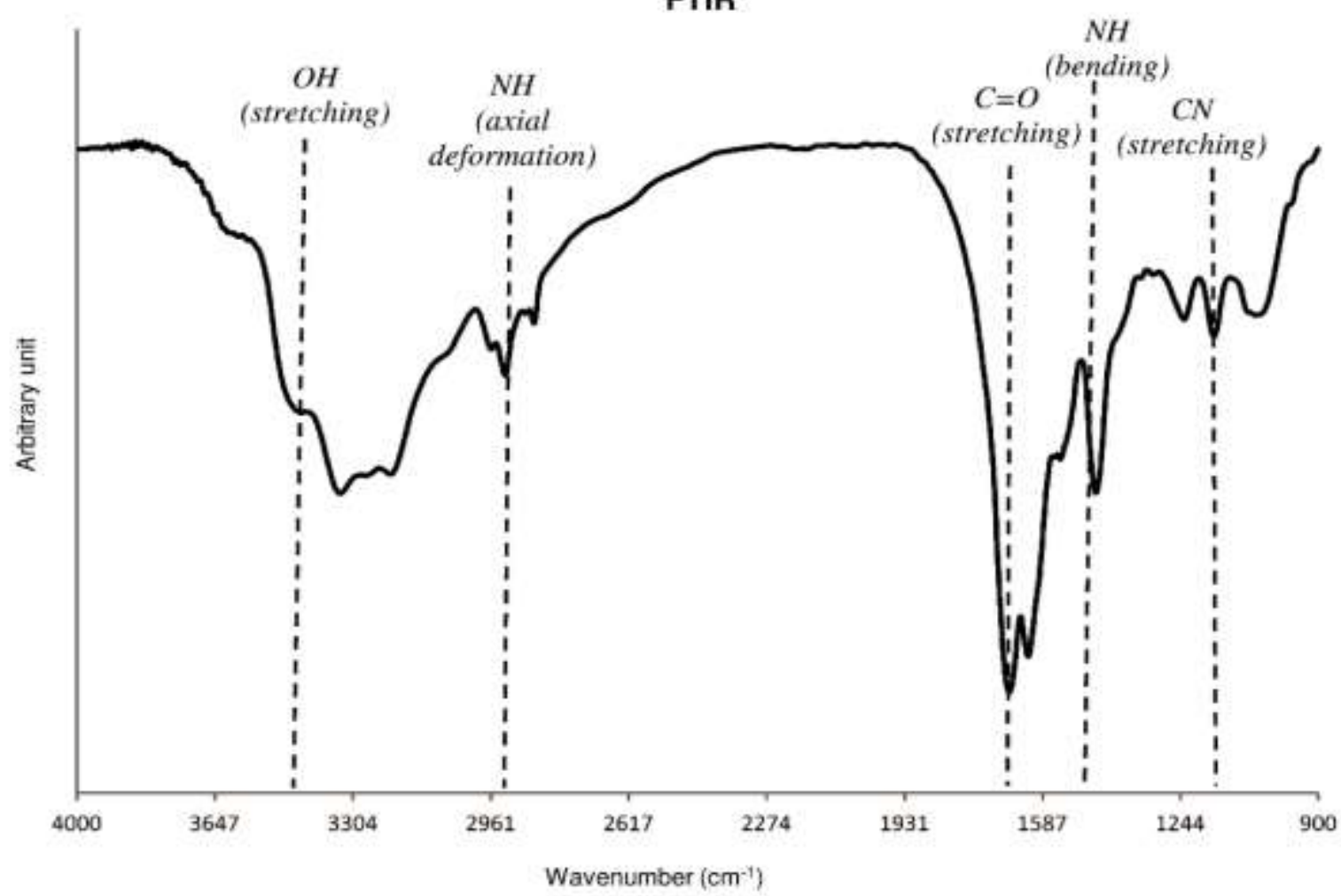

Figure 2. FTIR spectra of SPG. Dashed lines show peaks associated to SPG $(\mathrm{OH}$ stretching, $\mathrm{NH}$ axial deformation, $\mathrm{C}=\mathrm{O}$ stretching, $\mathrm{NH}$ bending and $\mathrm{CN}$ stretching).

XRD

The XRD investigation confirmed the predominantly amorphous profile of the SPG, with a degree of crystalline at 2-Theta Degrees of 22.40. These data demonstrate the amorphous character of this collagenlike material (Figure 3).

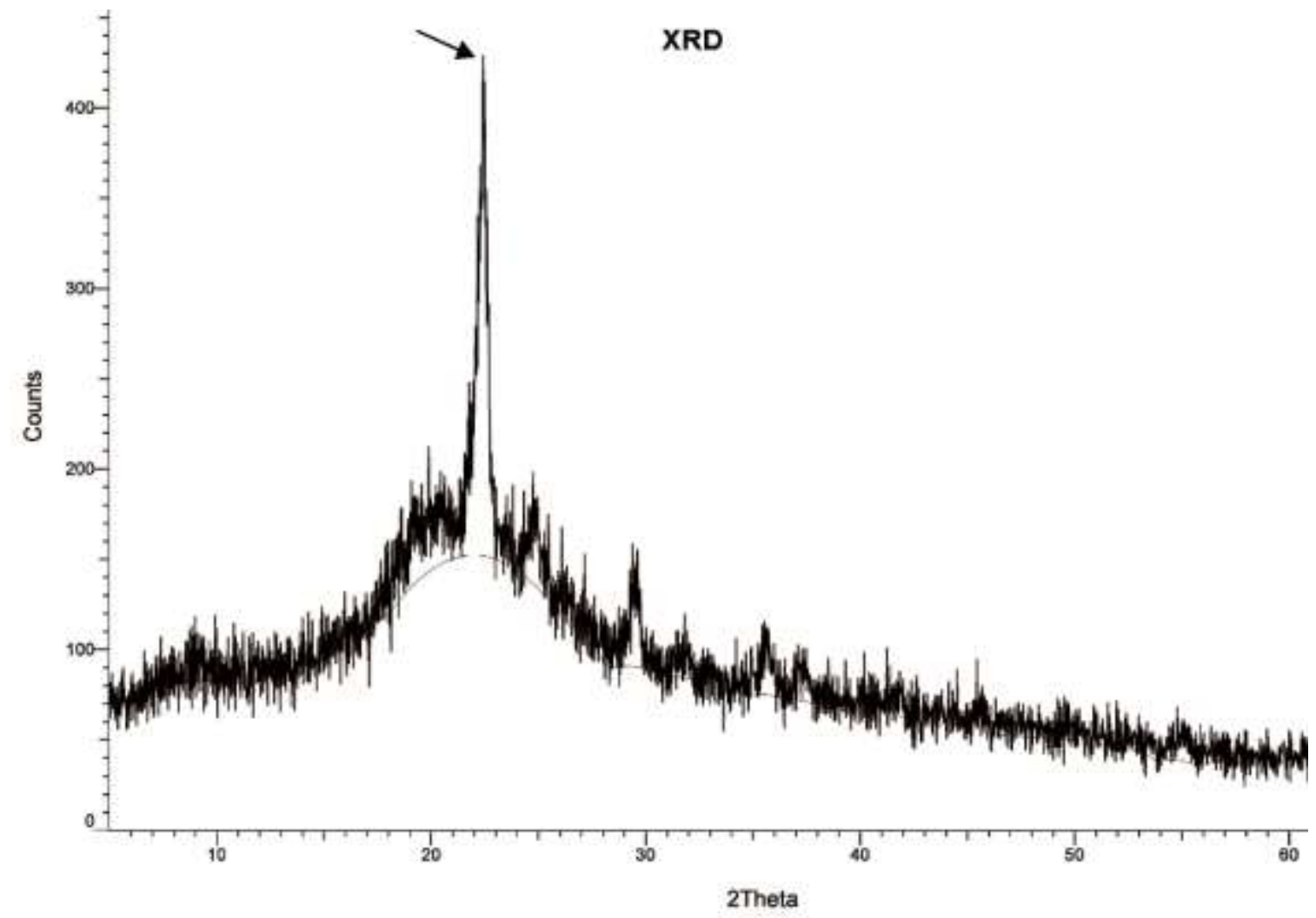

Figure 3. XRD diffraction pattern of SPG. A reduced crystalline peak was found at 2-Theta Degrees of 22.40 (arrow). 
AlamarBlue

\section{$L 929$}

Figure 4A demonstrates fibroblast viability by alamarBlue ${ }^{\circledR}$ after 1,3 and 7 days separated by groups. It is possible to observed a higher cell viability for L929 at 7 days compared to 1 day of seeding in all groups $\left({ }^{*} \mathrm{p}<0.05\right)$. Furthermore, in Figure $4 \mathrm{~B}$, no significant difference in the rate of increase in viability after 3 and 7 days of culture between the groups.

\section{MC3T3}

For the osteoblast viability assay, all groups demonstrated a higher cell viability at day 7 in comparison to day $1(p<0.01)$ (Figure $4 \mathrm{C})$. However, the comparisons among groups showed that the rate of viability increase was lower for SPG compared to Control $(p<0.0001)$ during the first 3 days, although no significant difference was observed between the groups when the whole period was considered (Figure 4D).

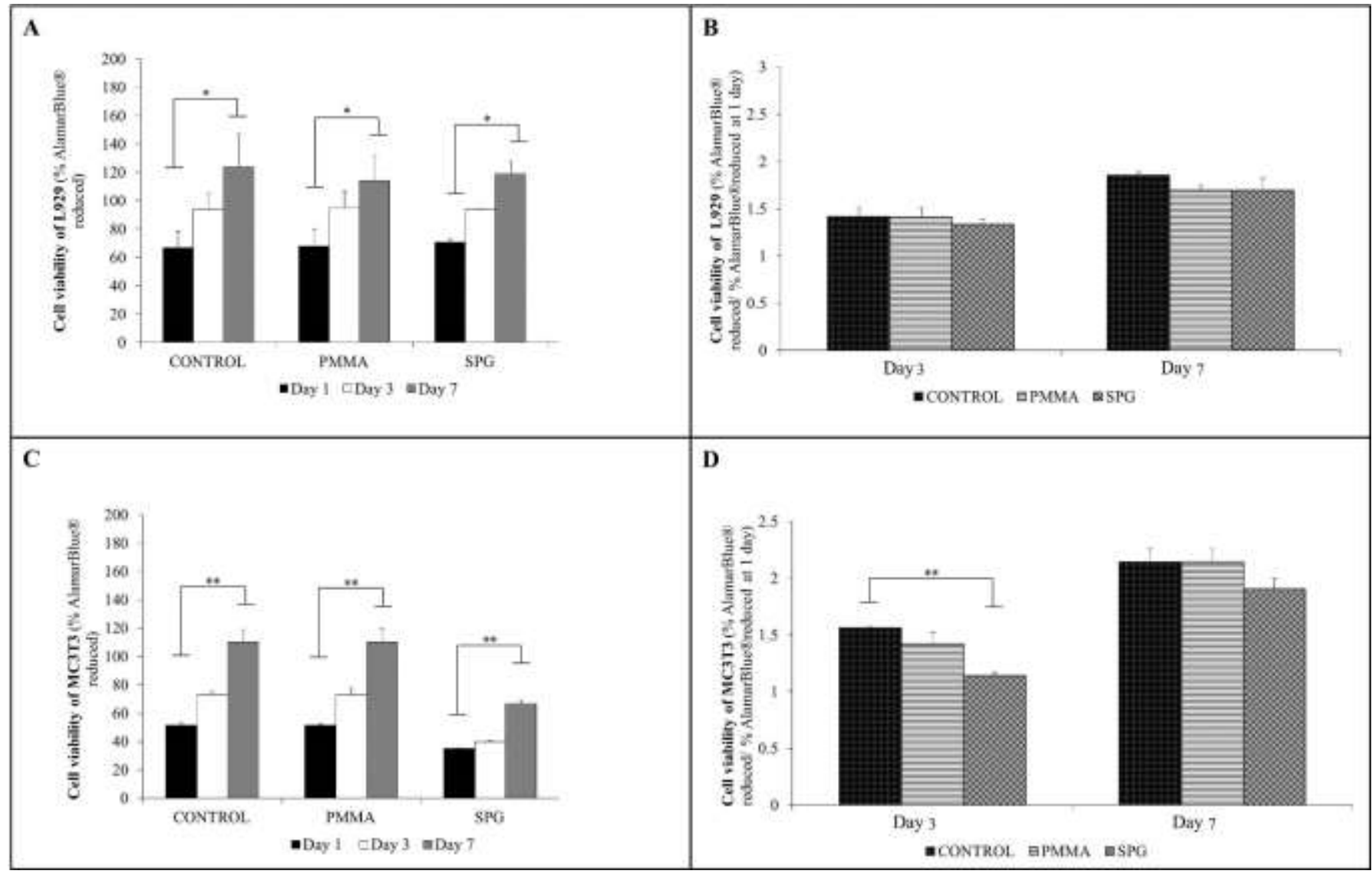

Figure 4. A: Cell viability of $L 929$ by alamarBlue ${ }^{\circledR}$ in Control medium and solution containing extract of PMMA and SPG after different experimental periods (1,3 and 7 days); B: Cell viability of L929 by \% alamarBlue ${ }^{\circledR}$ reduced at 3 and 7 days/ \% alamarBlue ${ }^{\circledR}$ reduced at 1 day) in Control medium and solution containing extract of PMMA and SPG; C: Cell viability of MC3T3 by alamarBlue ${ }^{\circledR}$ in Control medium and solution containing extract of PMMA and SPG after different experimental periods (1, 3 and 7 days); B: Cell viability of MC3T3 by $\%$ alamarBlue ${ }^{\circledR}$ reduced at 3 and 7 days/ \% alamarBlue ${ }^{\circledR}$ reduced at 1 day) in Control medium and solution containing extract of PMMA and SPG. ${ }^{*} p<0.05 ;{ }^{* *} p<0.01$ and ${ }^{* * *} \mathrm{p}<0.0001$.

\section{Histopathological analysis}

Figures 5 and 6 demonstrated the representative histological sections of PMMA and SPG, 15- and 45days post-surgery, in 2 different magnitudes (x2.5, x10 and x40). For PMMA, 15 days after implantation, material particles still could be observed, surrounded by granulation tissue, with some areas of newly formed bone at the borders of the defect and the presence of osteoblasts (Figure 5A, B and C). For SPG, degradation of the material was detected, with an intense ingrowth of granulation tissue. Some areas of newly formed bone tissue were observed at the borders of the defect and the presence of osteoblasts (Figure 5D, E and F). 


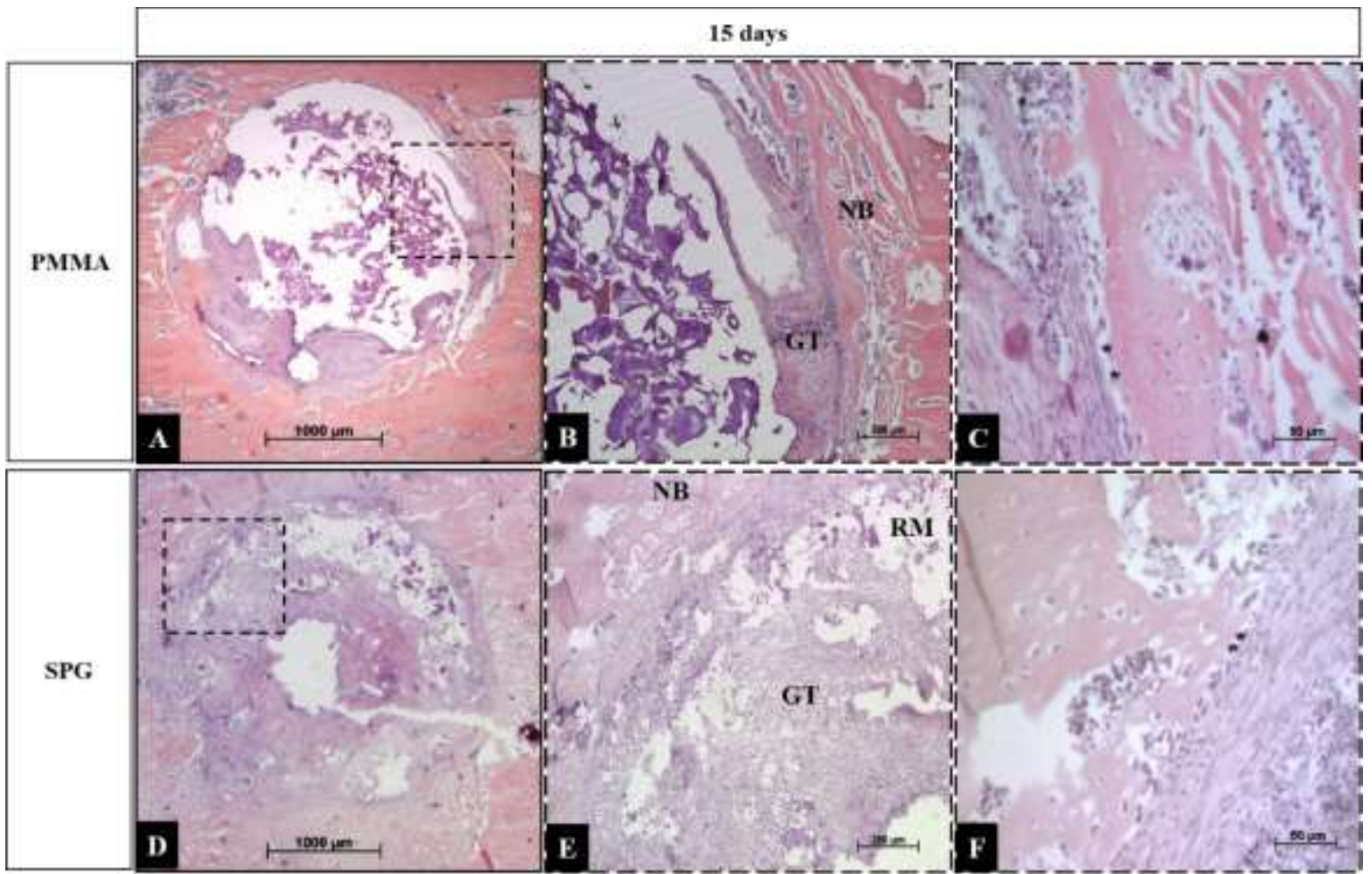

Figure 5. Representative histological sections of PMMA (A, B and C) and SPG (D, E and F) groups after 15 days. GT: granulation tissue; NB: newly bone; RM: residual material; *: osteoblast. Hematoxylin and eosin. Scale bar: $1000 \mu \mathrm{m}$ (mag. x2.5), $200 \mu \mathrm{m}$ (mag. x10) and $50 \mu \mathrm{m}$ (mag. x40).

After 45 days of implantation, it was observed the presence of osteoblasts and a complete degradation of the material with the bone defect being filled mostly with newly formed bone for both groups (Figure 6). However, a more mature aspect could be observed for SPG (Figure 6D, E and F).

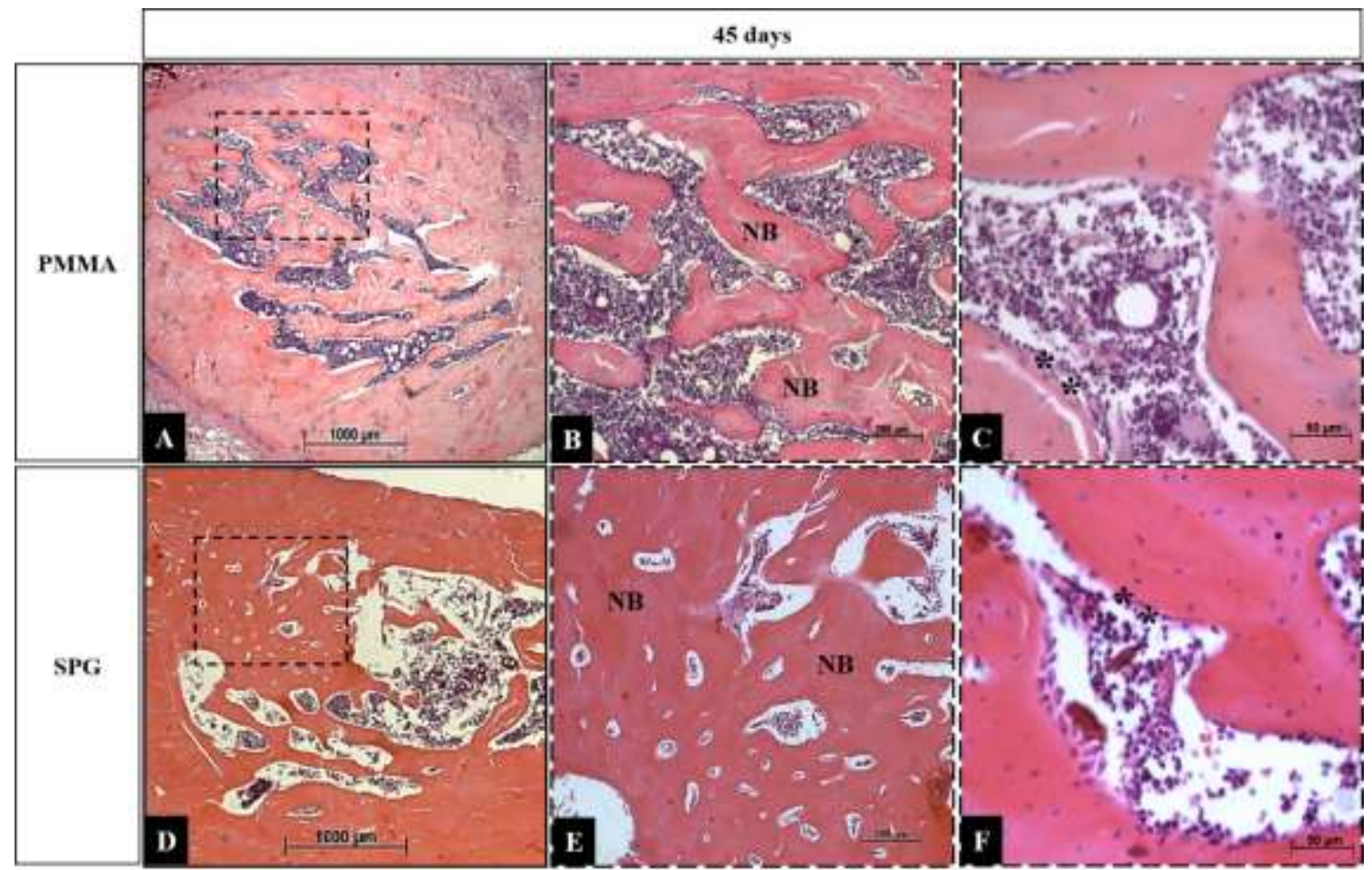

Figure 6. Representative histological sections of PMMA (A, B and C) and SPG (D, E and F) groups after 45 days. NB: newly bone. ${ }^{*}$ osteoblast. Hematoxylin and eosin. Scale bar: $1000 \mu \mathrm{m}$ (mag. x2.5), $200 \mu \mathrm{m}$ (mag. 10) and $50 \mu \mathrm{m}$ (mag. $x 40)$. 


\section{Histomorphometric analysis}

Figure 7 demonstrated that SPG demonstrated a higher value of $\%$ BV/TV compared to PMMA $(p=0.004)$ for both experimental periods. Moreover, for Ob.S/BS and for N.Ob/T.Ar, in the first experimental period, it was observed a significantly higher value for SPG compared to PMMA ( $p=0.031$ and 0.028 , respectively) (Figures 8 and 9).

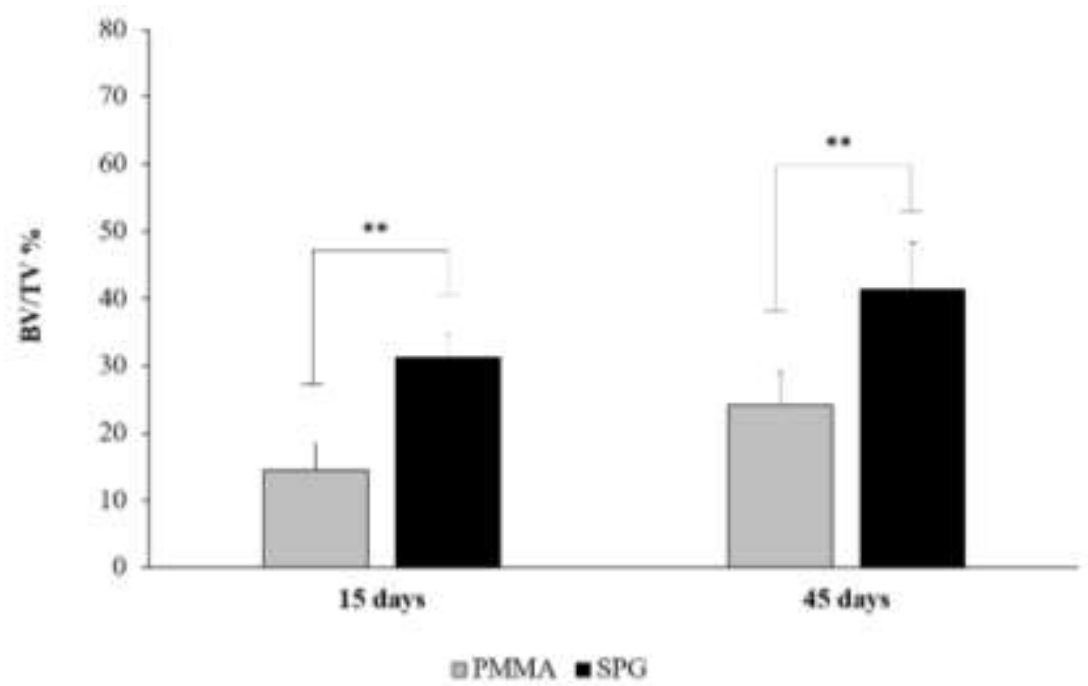

Figure 7. Means and standard deviation of $\%$ of BV/TV (bone volume per tissue volume). Dunn`s test. ${ }^{* *} \mathrm{p}<0.01$.

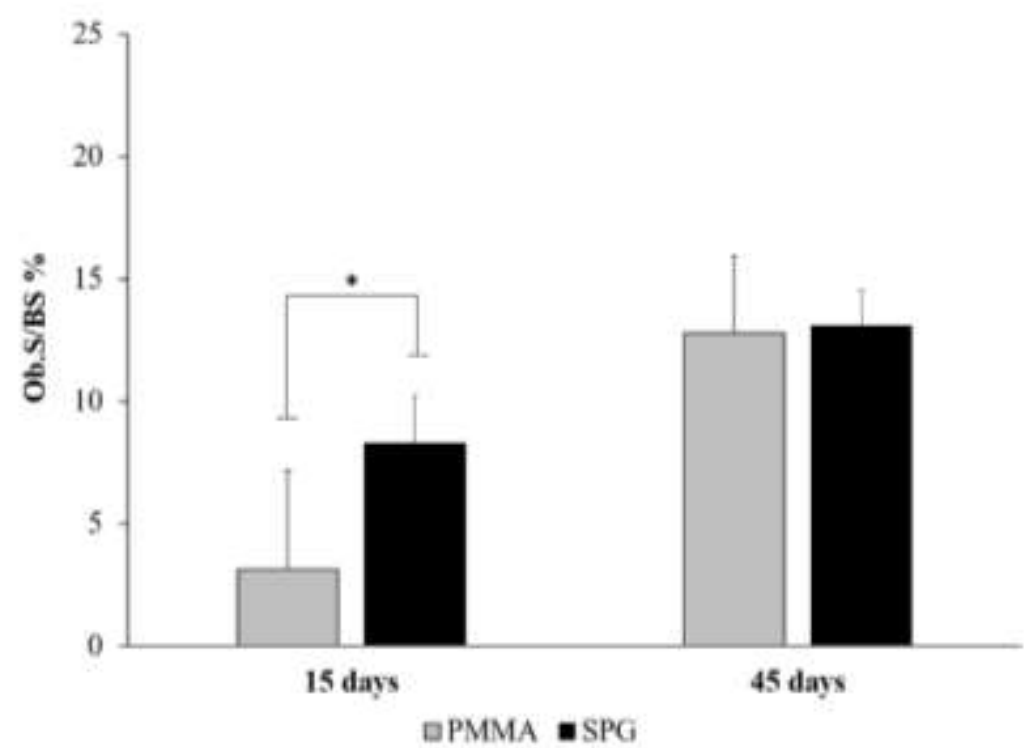

Figure 8. Means and standard deviation of $\%$ of Ob.S/BS (osteoblast surface per bone surface). $T$ test. ${ }^{*} p<0.05$.

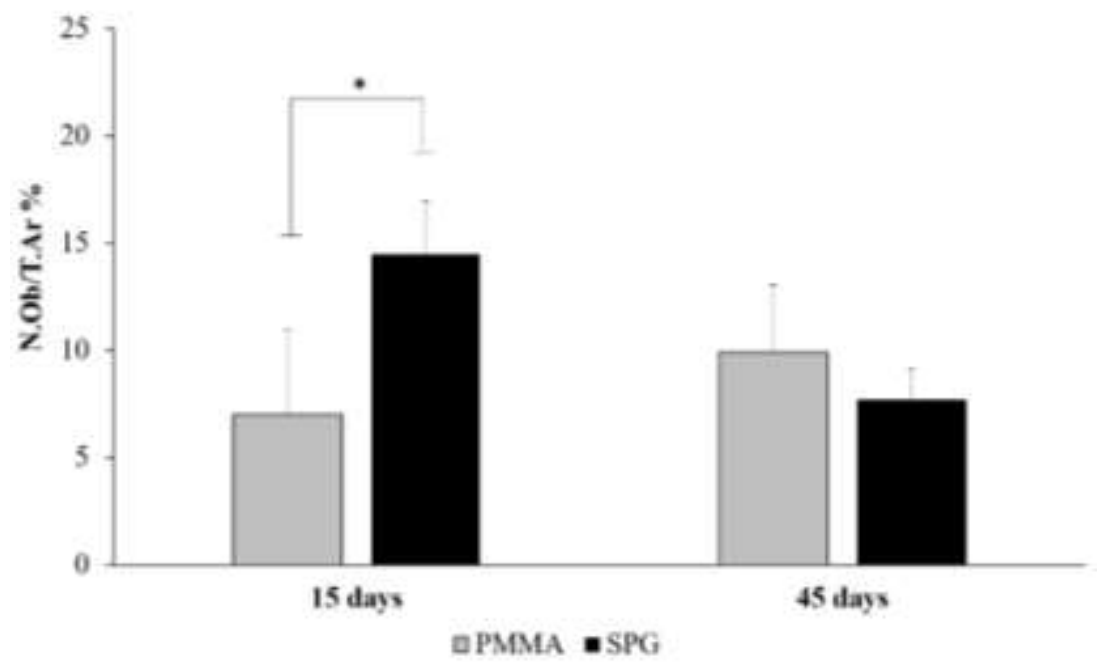

Figure 9. Means and standard deviation of $\%$ of N.Ob/T.Ar (number of osteoblast per tissue area). $T$ test. ${ }^{*} p<0.05$. 


\section{Biomechanical test}

No difference in the biomechanical test was observed between PMMA and SPG for any variable analyzed (Figure 10).

A

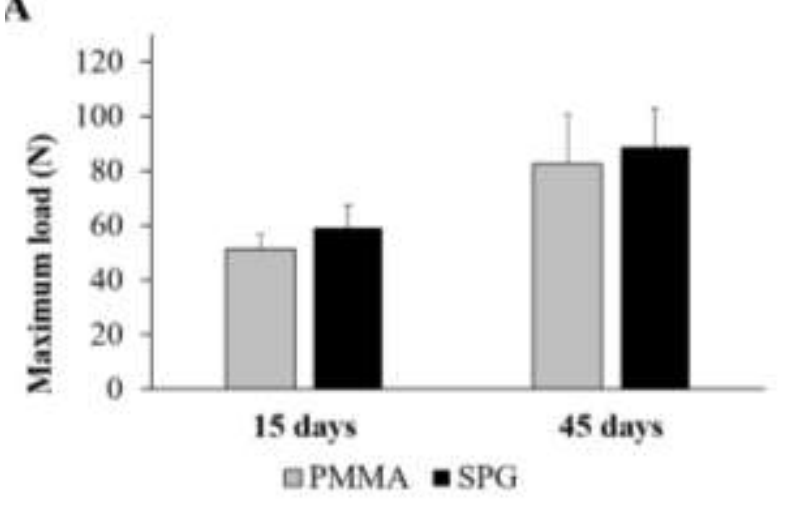

B

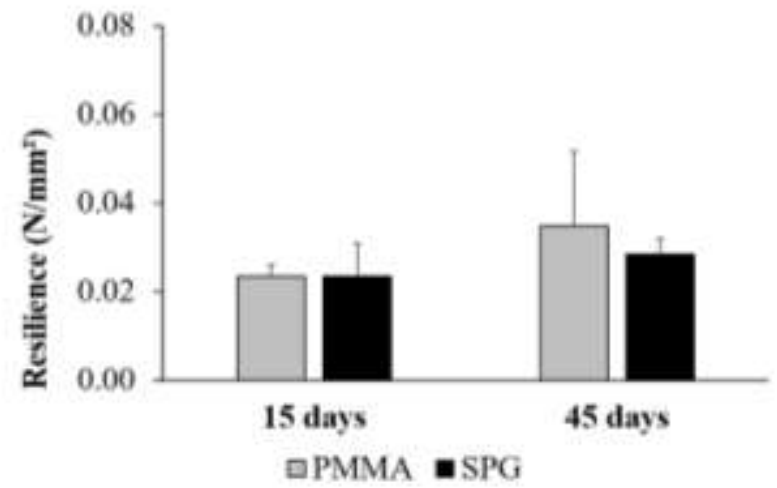

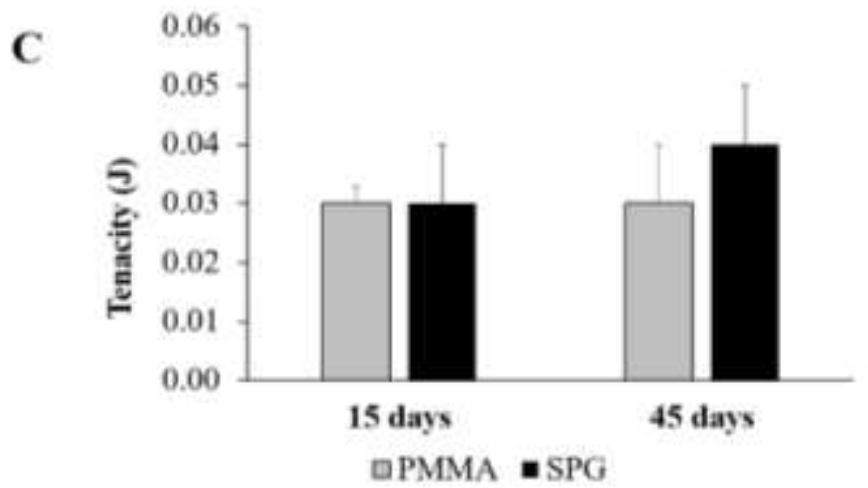

Figure 10. Means and standard deviation of \% for the biomechanical evaluation of the tibias (maximun load $(\mathrm{N})$, resilience $\left(\mathrm{N} / \mathrm{mm}^{2}\right)$ and tenacity $\left.(\mathrm{J})\right)$. T test. ${ }^{*} \mathrm{p}<0.05$.

\section{DISCUSSION}

The main purpose of the present study was to characterize the morphological aspects of marine collagen (spongin) extract from marine sponges, as well as, to evaluate its in vitro and in vivo biological performance. Our results demonstrated SPG presented an irregular granular aspect, with a composition of $\mathrm{OH}, \mathrm{C}=\mathrm{O}, \mathrm{NH}$, $\mathrm{CN}$ and an amorphous profile. Also, in vitro viability results for the L929 and MC3T3 cell lines cultured with SPG extracts demonstrated normal growth in comparison to controls, except MC3T3 viability at day 3. Furthermore, histology demonstrated that SPG treated animals presented an increased rate of material resorption and higher granulation and bone formation deposition in the region of the defect. These findings corroborate those of the histomorphometric analysis, which demonstrated higher values of BV/TV, Ob.S/BS, and N.Ob/T.Ar for SPG treated animals. Interestingly, the biomechanical test did not demonstrate any difference between groups.

It is well known that COL displays a palette of unique and numerous features, largely and advantageously exploited in the bone tissue engineering field [2,11]. Due to this importance, many different sources of collagen have been investigated, including the ones from marine sponges [2,11]. In the present study, it was possible to observe that the protocol used was successful to extract collagen from the Aplysina fulva specie.

Concerning the characterization studies, SEM images demonstrated the smooth and heterogeneous aspect of SPG in agreement with the findings of Tziveleka and coauthors [21]. Moreover, FTIR, which is a suitable analytical technique to depict the presence of major functional clusters in the samples [22], showed for SPG a broad band related to hydroxyl $(\mathrm{O}-\mathrm{H})$ of the water molecule at $3522 \mathrm{~cm}^{-1}$ [23]. Additionally, the peaks regarding the collagen-like nature of SPG must be highlighted as follows: amide I $(\mathrm{C}=\mathrm{O})$ at wavelength of $1644 \mathrm{~cm}^{-1}$; amide II (N-H) at $2900 \mathrm{~cm}^{-1}$ and $1510 \mathrm{~cm}^{-1}$; and amide III (C-N) at $1258 \mathrm{~cm}^{-1}$ [24]. All these findings demonstrate the conservation of the polypeptide chains of collagen even after the treatment used, in this work, for SPG obtainment. According to previous works, XRD assessment verified the predominantly amorphous profile of SPG, since it is a collagen-like material, exhibiting low crystalline domain [25]. Only a reduced crystalline peak was found at $\sim 22.40$, corresponding to the distance between amino acids in the 
collagen triple helix structure, and this fact was already showed earlier for collagen-based materials in the literature $[26,27]$.

The in vitro studies were performed to evaluate the biocompatibility of SPG and fibroblasts or preosteoblastic cells. Cell viability study demonstrated that all groups for L929 and MC3T3 cell lineages demonstrated an increase in cell viability on the seventh day compared to the first day after seeding. The improved cell viability over time demonstrate that PMMA and SPG do not cause cell death and allow cell proliferation, indicating that both materials are biocompatible. Additionally, in the analysis of comparison of cell viability between groups, it is possible to observe that there was no significant difference in L929 viability in the evaluated periods, which indicates that the cellular growth showed before had similar patterns among cells cultivated or not with materials. For MC3T3 viability, the results demonstrated a decrease in cell viability in the SPG compared to Control after 3 days and no significant difference between groups after 7 days. Taken together, it can be observed that SPG did not compromise the cell viability, with values close to control, demonstrating that the material is biocompatible and non-cytotoxic. These positive effects can be explained by the structure of SPG, which has been shown to be similar to collagen [2,5]. These results corroborate Silva et al. [2] that showed that the marine collagen of sponges is biocompatible and promotes cell viability. Additionally, a previous study that associated SPG to Hydroxyapatite (HA) demonstrated positive effects of the incorporation of SPG, improving the biological performance of HA [28].

Concerning the in vivo analysis, an adequate rate of material degradation is essential for bone ingrowth into bone defect areas, since formation of new bone tissue and ingrowth into the defect area needs the liberation of space $[29,30]$. The results of the current study indicate that SPG scaffolds degraded properly over time, which may result in a stimulus for bone formation. Also, no inflammatory process was observed in the defect region in the SPG treated animals. An exacerbated inflammatory response caused by biomaterials can culminate in an impairment of the process of tissue repair [31]. Also, it needs to be emphasized that the tissue response to an implanted biomaterial depends on its chemical composition, which determines the intensity of the foreign body reaction [31]. In this context, many studies demonstrated that Col has no cytotoxic effects and is biocompatible [32-39]. These findings are in line with the results of the current study, which demonstrated that SPG did not evoke any severe inflammatory responses.

Histomorphometry indicated that higher values of newly formed bone and number of osteoblasts were found in the SPG treated animals. The increased implant degradation observed for SPG scaffolds might be related to the increased dissolution of SPG when in contact with bone tissue [40,41]. resulting in lower amount of remaining implant material at an earlier time point compared to the slow degradable PMMA scaffolds. Also, it is likely that the superior biological performance of SPG is determined by the positive effects of the organic material on bone metabolism.

It is well known that bone strength depends not only on its geometry and architecture but also on its tissue composition [42]. The amount of bone mass is not the only parameter that influences tissue mechanical properties, but also the quality and arrangement of bone microstructural elements [43]. In this context, similar bone biomechanical properties observed for the experimental groups can be seen as a positive aspect. This phenomenon probably indicates that the presence of the materials and/or spatial distribution associated to the granulation tissue or newly formed bone in SPG treated animals culminated in the same bone strength compared to the PMMA group (which presented a higher amount of material into the defect area). It is necessary to emphasize that the bone defect model used in the present study was a non-critical one, which means that the process of healing happens spontaneously [44]. In this context, the use of a critical model is necessary to evaluate in more detail the behavior of composites in the process of non-spontaneous healing. Furthermore, biomaterials with different compositions and structure have been extensively studied for bone tissue engineering proposals. In this context, a composite material, including Biosilica (BS) enriched with marine collagen was tested. Indeed, BS induced a more appropriate response to stimulate bone metabolism and, interestingly, the incorporation of collagen did not increase the newly formed bone deposition however no difference between immunohistochemistry and biomechanical analysis were observed.

Although all the positive results of the present study, the effects of SPG need to be investigated in longterm studies and remain to be provided. Following this line, further investigations are necessary in order to validate these combinations as safe and efficient materials for biomedical applications.

Thus, marine sponge collagen has been emerging as a promising alternative from collagen derived from other sources such as bovine collagen and another marine collagen. The present study demonstrated that SPG from Aplysina fulva presented an irregular granular aspect, with a composition of $\mathrm{OH}, \mathrm{C}=\mathrm{O}, \mathrm{NH}, \mathrm{CN}$ and an amorphous profile. Also, in vitro viability results for the L929 and MC3T3 cell lines cultured with SPG extracts demonstrated normal growth in comparison to controls, except MC3T3 viability at day 3. Also, SPG treated animals demonstrated a higher amount of material degradation and newly formed bone in an 
experimental model of bone defect in rats. Taken together, all results suggest that marine collagen from the sponges can be considered as an alternative source of col for tissue engineering proposals.

Funding: This research was financed in part by the Coordenação de Aperfeiçoamento de Pessoal de Nível Superior (CAPES) - Finance Code 001, Fundação de Amparo à Pesquisa no Estado de São Paulo (FAPESP \#2016/13636-9 and \#2015/20704-8) and Conselho Nacional de Desenvolvimento Científico e Tecnológico (CNPq).

Conflicts of Interest: The authors declare no conflict of interest.

\section{REFERENCES}

1. Pozzolini M, Scarfi S, Gallus L, Castellano M, Vicini S, Cortese K, Gagliani MC, Bertolino M, Costa G, Giovine M (2018) Production, characterization and biocompatibility evaluation of collagen membranes derived from marine sponge Chondrosia reniformis Nardo, 1847. Mar Drugs 16 (4). doi:10.3390/md16040111

2. Silva TH, Moreira-Silva J, Marques AL, Domingues A, Bayon $Y$, Reis RL. Marine origin collagens and its potential applications. Mar Drugs. 2014,12(12):5881-901. doi:10.3390/md12125881

3. Lin Z, Solomon KL, Zhang X, Pavlos NJ, Abel T, Willers C, Dai K, Xu J, Zheng Q, Zheng M. In vitro evaluation of natural marine sponge collagen as a scaffold for bone tissue engineering. Int J Biol Sci. 2011, 7 (7):968-77. doi:10.7150/ijbs.7.968

4. Zdarta J, Norman LJ, Smulek W. Spongin-based scaffolds from Hippospongia communis Demosponge as an effective support for lipase immobilization. Catalysts. 2017,7:147. doi.org/10.3390/catal7050147

5. Hoyer B, Bernhardt A, Heinemann S, Stachel I, Meyer M, Gelinsky M. Biomimetically mineralized salmon collagen scaffolds for application in bone tissue engineering. Biomacromolecules. 2012,13(4):1059-66. doi:10.1021/bm201776r

6. Xiao S, Yuan X, Knoll AH. Eumetazoan fossils in terminal proterozoic phosphorites? Proc Natl Acad Sci U. 2000, S A 97 (25):13684-9. doi:10.1073/pnas.250491697

7. Muller WE, Wang X, Kropf K, Ushijima H, Geurtsen W, Eckert C, Tahir MN, Tremel W, Boreiko A, Schlossmacher $\mathrm{U}, \mathrm{Li}$ J, Schroder HC. Bioorganic/inorganic hybrid composition of sponge spicules: matrix of the giant spicules and of the comitalia of the deep sea hexactinellid Monorhaphis. J Struct Biol. 2008,161(2):188-203. doi:10.1016/j.jsb.2007.10.009

8. Green D, Howard D, Yang X, Kelly M, Oreffo ROC. Natural marine sponge fiber skeleton: A biomimetic scaffold for human osteoprogenitor cell attachment, growth, and differentiation. Tissue Engineering. 2003,9(6):1159-66. doi:Doi 10.1089/10763270360728062

9. Exposito JY, Cluzel C, Garrone R, Lethias C. Evolution of collagens. Anat Rec. 2002,268(3):302-16. doi:10.1002/ar.10162

10. Imatsubo T, Kishi R, Miura T, Ohzono T, Yamaguchi T. Formation of hydroxyapatite skeletal materials from hydrogel matrices via artificial biomineralization. J Phys Chem B. 2015,119(28):8793-9. doi:10.1021/acs.jpcb.5b03181

11. Swatschek D, Schatton W, Kellermann J, Muller WE, Kreuter J. Marine sponge collagen: isolation, characterization and effects on the skin parameters surface-pH, moisture and sebum. Eur J Pharm Biopharm. 2002,53(1):107-13. doi:10.1016/s0939-6411(01)00192-8

12. Sousa THS (2009) Projeto conceitual de implante bioativo com gradiente de estrutura funcional em PMMA e HA. Analises: in vitro e in vivo. Universidade de São Paulo, São Carlos.

13. Haach LCA (2015) Corpos compósitos de poli(metacrilato de metila) com microfibra de biovidro e poros para reparo de defeitos ósseos. Universidade de São Paulo, São Carlos.

14. Lopez-Heredia MA, Sa Y, Salmon P, de Wijn JR, Wolke JG, Jansen JA. Bulk properties and bioactivity assessment of porous polymethylmethacrylate cement loaded with calcium phosphates under simulated physiological conditions. Acta Biomater. 2012,8(8):3120-7. doi:10.1016/j.actbio.2012.05.007

15. Wang M, Ni Y, Cao L, Zhao D, Ma X. Porous Ni/beta-Ni(OH)2 superstructures: rapid solvothermal synthesis, characterization, and electrochemical property. J Colloid Interface Sci. 2013, 401:8-13. doi:10.1016/j.jcis.2013.01.016

16. Shin H, Quinten Ruhe P, Mikos AG, Jansen JA. In vivo bone and soft tissue response to injectable, biodegradable oligo(poly(ethylene glycol) fumarate) hydrogels. Biomaterials. 2003,24(19):3201-11.doi:10.1016/s01429612(03)00168-6

17. Magri AM, Fernandes KR, Assis L, Mendes NA, da Silva Santos AL, de Oliveira Dantas E, Renno AC. Photobiomodulation and bone healing in diabetic rats: evaluation of bone response using a tibial defect experimental model. Lasers Med Sci. 2015,30(7):1949-57. doi:10.1007/s10103-015-1789-3

18. Magri AMP, Fernandes KR, Ueno FR, Kido HW, Da Silva AC, Braga FJC, Granito RN, Gabbai-Armelin PR, Rennó ACM (2017) Osteoconductive properties of two different bioactive glass forms (powder and fiber) combined with collagen. Applied Surface Science 423:557-65. doi:10.1016/j.apsusc.2017.06.152 
19. Fernandes KR, Magri AMP, Kido HW, Parisi JR, Assis L, Fernandes KPS, Mesquita-Ferrari RA, Martins VC, Plepis AM, Zanotto ED, Peitl O, Renno ACM (2017) Biosilicate/PLGA osteogenic effects modulated by laser therapy: In vitro and in vivo studies. J Photochem Photobiol B 173:258-65. doi:10.1016/j.jphotobiol.2017.06.002

20. Gabbai-Armelin PR, Souza MT, Kido HW, Tim CR, Bossini PS, Magri AM, Fernandes KR, Pastor FA, Zanotto ED, Parizotto NA, Peitl O, Renno AC. Effect of a new bioactive fibrous glassy scaffold on bone repair. 2015, J Mater Sci Mater Med 26 (5):177. doi:10.1007/s10856-015-5516-1

21. Tziveleka LA, loannou E, Tsiourvas D, Berillis P, Foufa E, Roussis V. Collagen from the marine sponges Axinella cannabina and Suberites carnosus: Isolation and morphological, biochemical, and biophysical characterization. 2017, Mar Drugs 15(6). doi:10.3390/md15060152

22. Riaz T, Zeeshan R, Zarif F, llyas K, Muhammad N, Safi SZ, Rahim A, Rizvi SAA, Rehman IU. FTIR analysis of natural and synthetic collagen. Appl Spectrosc Rev. 2018,53(9):703-46. doi:10.1080/05704928.2018.1426595

23. Bayari SH, Sen EH, Ide S, Topaloglu B. Structural studies on Demospongiae sponges from Gokceada Island in the Northern Aegean Sea. Spectrochim Acta A Mol Biomol Spectrosc. 2018,192:368-77. doi:10.1016/j.saa.2017.11.046

24. Zdarta J, Antecka K, Frankowski R, Zgola-Grzeskowiak A, Ehrlich H, Jesionowski T. The effect of operational parameters on the biodegradation of bisphenols by Trametes versicolor laccase immobilized on Hippospongia communis spongin scaffolds. 2018, Sci Total Environ 615:784-95. doi:10.1016/j.scitotenv.2017.09.213

25. Badii F, MacNaughtan W, Mitchell JR, Farhat IA. The effect of drying temperature on physical properties of thin gelatin films. 2014, Dry Technol 32 (1):30-8. doi:10.1080/07373937.2013.808206

26. Shi D, Liu F, Yu Z, Chang B, Goff HD, Zhong F. Effect of aging treatment on the physicochemical properties of collagen films. Food Hydrocolloids. 2019, 87:436-47. doi:10.1016/j.foodhyd.2018.08.016

27. Chen Z, Mo X, He C, Wang H. Intermolecular interactions in electrospun collagen-chitosan complex nanofibers. Carbohydr Polym. 2008,72(3):410-18

28. Parisi JR, Fernandes KR, Avanzi IR, Dorileo BP, Sant. doi:10.1016/j.carbpol.2007.09.018ana AF, Andrade AL, Gabbai-Armelin PR, Fortulan CA, Triches ES, Granito RN, Renno ACM. Incorporation of collagen from marine sponges (spongin) into hydroxyapatite samples: characterization and in vitro biological evaluation. Mar Biotechnol (NY). 2018, 21:20-7. doi:10.1007/s10126-018-9855-z

29. Van de Watering FCJ, van den Beucken J, Walboomers XF, Jansen JA. Calcium phosphate/poly(D,L-lactic-coglycolic acid) composite bone substitute materials: evaluation of temporal degradation and bone ingrowth in a rat critical-sized cranial defect. Clin Oral Implants Res. 2012,23(2):151-9. doi:10.1111/j.1600-0501.2011.02218.x

30. Lee JH, Nam H, Ryu HS, Seo JH, Chang BS, Lee CK. Bioactive ceramic coating of cancellous screws improves the osseointegration in the cancellous bone. J Orthop Sci. 2011,16(3):291-7. doi:10.1007/s00776-011-0047-1

31. Anderson J, McNally A (2011) Biocompatibility of implants: lymphocyte/macrophage interactions. Semin Immunopathol 33 (3):221-33. doi:10.1007/s00281-011-0244-1

32. Link D, van den Dolder J, van den Beucken J, Cuijpers V, Wolke J, Mikos A, Jansen J. Evaluation of the biocompatibility of calcium phosphate cement/PLGA microparticle composites. J Biomed Mater Res A 87. 2008,(3):760-9. doi:10.1002/jbm.a.31831

33. Bodde E, Cammaert C, Wolke J, Spauwen P, Jansen J.7) Investigation as to the osteoinductivity of macroporous calcium phosphate cement in goats. J Biomed Mater Rest B Appl Biomater 83B.2007,(1):161-8. doi:10.1002/jbm.b.30780

34. Moura J, Teixeira LN, Ravagnani C, Peitl O, Zanotto ED, Beloti MM, Panzeri H, Rosa AL, de Oliveira PT. In vitro osteogenesis on a highly bioactive glass-ceramic (Biosilicate®). J Biomed Mater Res A 82. 2007, (3):545-57. doi:10.1002/jbm.a.31165

35. Félix Lanao RP, Leeuwenburgh SCG, Wolke JGC, Jansen JA. Bone response to fast-degrading, injectable calcium phosphate cements containing PLGA microparticles. Biomaterials. 2011,32(34):8839-47. doi:10.1016/j.biomaterials.2011.08.005

36. van de Watering FCJ, van den Beucken JJJP, Walboomers XF, Jansen JA. Calcium phosphate/poly(d,I-lactic-coglycolic acid) composite bone substitute materials: evaluation of temporal degradation and bone ingrowth in a rat critical-sized cranial defect. Clin Oral Implants Res. 2012, 23 (2):151-9. doi:10.1111/j.1600-0501.2011.02218.x

37. Day RM, Maquet $V$, Boccaccini $A R$, Jérôme R, Forbes $A$. In vitro and in vivo analysis of macroporous biodegradable poly(D,L-lactide-co-glycolide) scaffolds containing bioactive glass. J Biomed Mater Res. 2005, A 75 (4):778-87. doi:10.1002/jbm.a.30433

38. Vargas GE, Mesones RV, Bretcanu O, López JMP, Boccaccini AR, Gorustovich A (2009) Biocompatibility and bone mineralization potential of $45 \mathrm{~S} 5$ Bioglass ${ }^{\circledR}$-derived glass-ceramic scaffolds in chick embryos. Acta Biomater 5 (1):374-80. doi:10.1016/j.actbio.2008.07.016 
39. Vogel M, Voigt C, Knabe C, Radlanski RJ, Gross UM, Müller-Mai CM (2004) Development of multinuclear giant cells during the degradation of Bioglass ${ }^{\circledR}$ particles in rabbits. J Biomed Mater Res A 70 (3):370-9. doi:10.1002/jbm.a.30048

40. Hoppe A, Güldal NS, Boccaccini AR. A review of the biological response to ionic dissolution products from bioactive glasses and glass-ceramics. Biomaterials. 2011, 32 (11):2757-74. doi:10.1016/j.biomaterials.2011.01.004

41. Rahaman MN, Day DE, Sonny Bal B, Fu Q, Jung SB, Bonewald LF, Tomsia AP. Bioactive glass in tissue engineering. Acta Biomater. 2011,7(6):2355-73. doi:10.1016/j.actbio.2011.03.016

42. Lirani-Galvao AP, Jorgetti V, da Silva OL. Comparative study of how low-level laser therapy and low-intensity pulsed ultrasound affect bone repair in rats. Photomed Laser Surg. 2006,24(6):735-40. doi:10.1089/pho.2006.24.735

43. de Oliveira RC, de Oliveira FH, Cestari TM, Taga R, Granjeiro JM. Morphometric evaluation of the repair of criticalsize defects using demineralized bovine bone and autogenous bone grafts in rat calvaria. Clin Oral Implants Res. 2008,19(8):749-54

44. Hoerth RM, Seidt BM, Shah M, Schwarz C, Willie BM, Duda GN, Fratzl P, Wagermaier W. Mechanical and structural properties of bone in non-critical and critical healing in rat. Acta Biomater. 2014,10(9):4009-19. doi:10.1016/j.actbio.2014.06.003

(C) 2021 by the authors. Submitted for possible open access publication under the terms and
conditions of the Creative Commons Attribution (CC BY NC) license
(https://creativecommons.org/licenses/by-nc/4.0/). 